\title{
Cost-Effectiveness Analysis of Maternal Immunisation Against Group B Streptococcus (GBS) Disease: a Modelling Study.
}

Kyriaki Giorgakoudia,1, Kyriaki.Giorgakoudi@brunel.ac.uk, Catherine O'Sullivan ${ }^{\mathrm{b}}$, cosulliv@sgul.ac.uk, Paul T. Heath ${ }^{\mathrm{b}}$, pheath@sgul.ac.uk, Shamez Ladhani ${ }^{\mathrm{b}, \mathrm{c}}$, Shamez.Ladhani@phe.gov.uk, Theresa Lamagni ${ }^{\mathrm{d}}$, Theresa.Lamagni@phe.gov.uk, Mary Ramsayc $^{c}$ Mary.Ramsay@phe.gov.uk, Hareth Al-Janabi , H.AlJanabi@bham.ac.uk, Caroline Trotter ${ }^{\mathrm{a}}$ clt56@cam.ac.uk

aDepartment of Veterinary Medicine, University of Cambridge, Cambridge, UK

${ }^{b}$ Vaccine Institute, Institute of Infection and Immunity, St George's University of London, London, UK

${ }^{\mathrm{c} I m m u n i s a t i o n, ~ H e p a t i t i s ~ a n d ~ B l o o d ~ S a f e t y ~ D e p a r t m e n t, ~ N a t i o n a l ~ I n f e c t i o n ~ S e r v i c e, ~ P u b l i c ~}$ Health England, London UK

${ }^{\mathrm{d}}$ Healthcare-Associated Infection \& Antimicrobial Resistance Department, National Infection Service, Public Health England, London UK

${ }^{\mathrm{e}}$ Institute of Applied Health Research, University of Birmingham, Birmingham, UK

Correspondence to:

Kyriaki Giorgakoudi, Kyriaki.Giorgakoudi@brunel.ac.uk

Institute of Environment, Health and Societies, Brunel University London, Uxbridge, UK

\footnotetext{
${ }^{1}$ Present address: Institute of Environment, Health and Societies, Brunel University London, Uxbridge, UK
} 


\section{Abstract}

2 Background: There is a considerable global burden of invasive group B streptococcal (GBS)

3 disease. Vaccines are being developed for use in pregnant women to offer protection to

4 neonates.

5 Objective: To estimate the potential impact and cost-effectiveness of maternal immunisation against neonatal and maternal invasive GBS disease in the UK.

7 Methods: We developed a decision-tree model encompassing GBS-related events in infants and mothers, following a birth cohort with a time horizon equivalent to average life expectancy (81 years). We parameterised the model using contemporary data from disease surveillance and outcomes in GBS survivors. Costs were taken from NHS sources and research studies. Maternal immunisation in combination with risk-based intrapartum antibiotic prophylaxis (IAP) was compared to the current standard practice of risk-based IAP alone from an NHS and Personal Social Services (health-provider) perspective. We estimated the cases averted and cost per QALY gained through vaccination. One-way sensitivity analysis, scenario analysis and probabilistic sensitivity analysis were performed.

Results: An effective maternal immunisation programme could substantially reduce the burden of GBS disease. The deterministic analysis estimated the threshold cost-effective price for a GBS vaccine to be $£ 54$ per dose at $£ 20,000$ /QALY ( $£ 71$ per dose at $£ 30,000$ /QALY). Results were most sensitive to assumptions on disease incidence, sequelae rate and vaccine efficacy. Probabilistic analysis showed $90.66 \%$ of iterations fell under the $£ 30,000$ threshold at a vaccine price of $£ 55$. Inclusion of modest prevention of stillbirths and/or, preterm births, carer health impacts, maternal GBS deaths and $1.5 \%$ discounting improved cost-effectiveness compared to the base case. Lowering vaccine strain coverage made the vaccine less cost-effective. A key limitation is that the properties of the final GBS vaccine are 
unknown.

Conclusions: Maternal GBS immunisation is expected to be cost-effective, even at a relatively high vaccine price.

Keywords: Group B Streptococcus; vaccine; infant; pregnancy; infectious disease; costeffectiveness analysis

\section{Introduction}

In the UK, group B Streptococcus (GBS; Streptococcus agalactiae) is a leading cause of meningitis and septicaemia in babies up to 3 months of age. A recent national prospective study showed GBS was responsible for half of all neonatal meningitis cases [1]. Invasive infant GBS disease has a case fatality rate of $5-10 \%$ in the UK [1-3], despite the availability of sophisticated neonatal intensive care. Up to $50 \%$ of GBS meningitis survivors have adverse neurodevelopmental outcomes [4]. GBS is also implicated as a cause of stillbirth $[5,6]$, pre-term birth $[6,7]$ and maternal sepsis $[6,8]$.

GBS is part of the natural flora of the human gastrointestinal and genitourinary tracts.

Asymptomatic carriage is common, with $20 \%$ of pregnant women in developed countries carrying GBS rectovaginally [9]. Around 50\% of infants born to colonised mothers will become colonised and 1\% will develop GBS disease [7]. Because maternal colonisation is a necessary stage in the disease process, at least for early onset disease (defined as $<7$ days of age), intervention strategies have, to date, focussed on prophylactic antibiotics for women in labour targeted on the basis of antenatal screening results and/or identified risk factors [10].

The incidence of GBS disease has increased in the UK since 2004 [1,11]; enhanced surveillance studies from the British Paediatric Surveillance Unit (BPSU) reported incidence of 0.72 per 1000 livebirths in 2004 [3] and 0.97 per 1000 livebirths in 2015 [2]. This increase 
is despite the UK prevention strategy of risk factor-based intrapartum antibiotic prophylaxis (IAP) [12]. The UK has not adopted universal antenatal screening because it is not clear whether the benefits of screening outweigh the harms for the majority of pregnant women [13]. Maternal immunisation strategies offer promise for the prevention of infant GBS disease without reliance on widespread antibiotic use and several vaccine candidates are in development [14].

Any new vaccine being considered for introduction into the UK immunisation programme must be supported with evidence of cost-effectiveness. A previous study [15] examined the cost-effectiveness of interventions against infant GBS disease in the UK, including maternal immunisation. This analysis emphasised that further research should prioritise the realisation of a GBS vaccine, although at this time vaccination was still a distant prospect. Other studies on the cost-effectiveness of GBS vaccines have been published more recently, including a study exploring the South African case [16], a study in sub-Saharan Africa [17] and two based in the USA $[18,19]$. The aim of this paper is to estimate the potential cost-effectiveness of GBS vaccine in the current UK context in order to inform both vaccine development and decision-making once a vaccine is licensed.

\section{Methods}

\section{Model description}

A static decision tree model was developed to account for infant GBS disease and long-term health outcomes, including death, among an annual cohort of UK livebirths (Error!

Reference source not found.). Maternal GBS disease was estimated separately based on the incidence of disease among maternities (excluding miscarriages). Stillbirths were included in 
the estimation of vaccination costs, however, the potential impact of the vaccine on the prevention of both stillbirths and preterm births was only explored in scenario analysis.

74 The cohort of livebirths was assumed to be homogenous and was based on 2014 data reporting 776,352 livebirths in the UK [20-22]. Infants were followed over their lifetime to enable the inclusion of health outcomes and healthcare costs over this period. The adopted time horizon was the life expectancy of survivors with no or mild sequelae, which was 81 years [23]. There were 3,563 stillbirths in the UK in 2014 [20,24,25] and these were included in the estimation of maternal immunisation costs (vaccine purchase and administration).

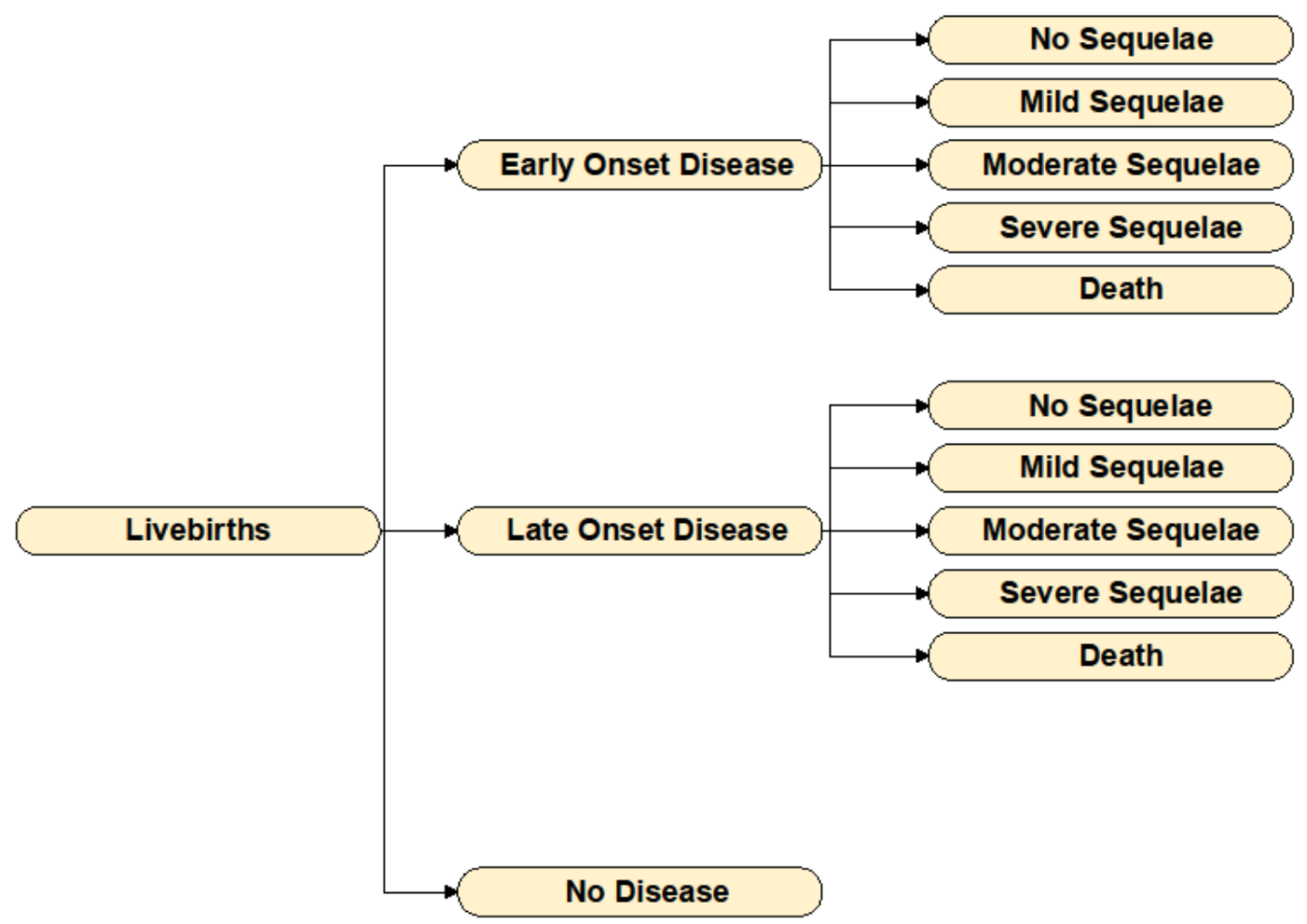

81 Figure 1.Diagram of decision tree model for base case scenario. The structure of the model remains the same for both strategies; risk factor-based IAP and maternal immunisation with risk factor-based IAP. Incremental health benefits of the latter strategy were estimated for the annual livebirths population (776,352 in 2014 data) with vaccination costs estimated for both livebirths and stillbirths 
(3,563 in 2014). The potential impact of strategies on maternal disease (all maternities excluding miscarriage) is estimated separately.

The current prevention strategy against infant GBS disease within the UK is one of risk factor-based IAP. The risk factors are a previous baby with GBS disease, maternal GBS carriage discovered during pregnancy, preterm birth, prolonged rupture of membranes, suspected maternal intrapartum infection and pyrexia [26]. Assuming that vaccinated pregnant women will still be provided with IAP in the presence of risk factors, we estimated the incremental cost-effectiveness of a maternal immunisation strategy in combination with risk factor-based IAP using the current standard practice of risk factor-based IAP alone as a comparator. For this reason, any savings that may arise through reduced antibiotic use and associated care were ignored; making our results more conservative. The model choice was based on the assumption that a GBS vaccine will not affect colonisation [27,28] and that maternal immunisation will offer protection for only a single pregnancy which is also a conservative approach in regard to the benefits of a GBS vaccine.

The model was computationally implemented in $\mathrm{R}$ using standard packages, and used to investigate costs and benefits of maternal immunisation from the perspective of the NHS and Personal Social Services (health provider). We followed standard methods on costeffectiveness analysis; the Joint Committee on Vaccination and Immunisation (JCVI), who make vaccine recommendations in the UK, in principle follow NICE methodology although more specific detail on dealing with uncertainty is given [29].

\section{Parameter values - Disease}

The latest available UK data on GBS disease and sequelae were used to parameterise the model. GBS disease incidence was informed by the most recent BPSU enhanced surveillance 
study for infants up to 3 months of age [2]. Case fatality rates were based on the same source,

110 while UK-wide data on livebirths and stillbirths were obtained from the Office for National

111 Statistics [22,30-33]. Parameter estimates are presented in Table 1.

112 Preliminary data from a follow-up study of survivors of GBS disease were used to estimate

113 disease after-effects (Heath et al unpublished). Survivors were followed-up 3 to 5 years after

114 recovery with quality of life assessments and neurodevelopmental outcomes. Sequelae

115 stratified by severity (mild, moderate and severe) along with quality-adjusted life year

116 (QALY) loss for each severity group were estimated (Appendix 1). Life expectancy data for

117 the general population [23] and GBS survivors [52-54](Appendix 1) were included in the

118 model to encompass the full lifetime impact of GBS disease on cases. 
Table 1. Base case parameter values of deterministic analysis and parameter distributions of probabilistic sensitivity analysis.

\begin{tabular}{|c|c|c|c|}
\hline Parameter & Base value & Distribution & Source \\
\hline \multicolumn{4}{|l|}{ Infant disease } \\
\hline GBS disease incidence & $0.97 / 1,000$ livebirths & unif(0.000873,0.001067) & {$[2]$} \\
\hline EOD incidence & $0.58 / 1,000$ livebirths & unif(0.000522,0.000638) & [2] \\
\hline LOD incidence & $0.39 / 1,000$ livebirths & unif(0.000351,0.000429) & {$[2]$} \\
\hline Severe sequelae rate & $\begin{array}{l}0.055 \text { (EOD), } 0.053 \\
\text { (LOD) }\end{array}$ & $\begin{array}{l}\text { unif(0.0495, 0.0605) (EOD), unif(0.0477, } \\
0.0583) \text { (LOD) }\end{array}$ & Based on Heath et al unpublished \\
\hline Moderate sequelae rate & $\begin{array}{l}0.096 \text { (EOD), } 0.092 \\
\text { (LOD) }\end{array}$ & $\begin{array}{l}\text { unif(}(0.0864,0.1056) \text { (EOD), unif }(0.0828 \\
0.1012) \text { (LOD) }\end{array}$ & Based on Heath et al unpublished \\
\hline Life expectancy in years (GBS sequelae) & $\begin{array}{l}25 \text { (severe), } 71 \\
\text { (moderate), } 81 \text { (mild) }\end{array}$ & $\begin{array}{l}\text { Triangular( } 11,25,43) \text { (severe), Triangular(43, } \\
71,81) \text { (moderate) }\end{array}$ & $\begin{array}{l}\text { Based on: severe [34], moderate- } \\
{[23,34], \text { mild }-[23,34]}\end{array}$ \\
\hline Disease diagnoses & $\begin{array}{l}\text { EOD: } 63.0 \% \text { (sepsis), } \\
3.1 \% \text { (meningitis), } 23.9 \% \\
\text { (pneumonia) }\end{array}$ & Not tested & {$[2]$} \\
\hline
\end{tabular}




\begin{tabular}{|c|c|c|c|}
\hline & $\begin{array}{l}\text { LOD: } 63.3 \% \text { (sepsis), } \\
34.9 \% \text { (meningitis), } 1.8 \% \\
\text { (pneumonia) }\end{array}$ & Not tested & [2] \\
\hline Maternal GBS disease incidence & $0.27 / 1,000$ maternities & unif(0.000243, 0.000297) & Based on [35] \\
\hline \multicolumn{4}{|l|}{ General population } \\
\hline Livebirths (yearly) & 776,352 & & {$[20-22]$} \\
\hline Stillbirths (yearly) & 3,563 & & {$[20,24,25]$} \\
\hline \multicolumn{4}{|l|}{ Vaccine } \\
\hline Vaccine strain coverage (pentavalent) & 0.962 & Triangular(0.8658,.962, 1) & [2] \\
\hline Vaccine adverse reaction rate & $\begin{array}{l}0.01(\mathrm{GP}) \text { and } 0.003 \\
\text { (anaphylaxis) }\end{array}$ & $\operatorname{Beta}(1,99)(\mathrm{GP})$ and $\operatorname{Beta}(3,997)$ (anaphylaxis) & $\begin{array}{l}\text { GP - assumed, no data available } \\
\text { Anaphylaxis - [39] }\end{array}$ \\
\hline \multicolumn{4}{|l|}{ Economic costs $(\mathfrak{E})$} \\
\hline $\begin{array}{l}\text { Healthcare costs per infant case (first } 2 \\
\text { years) }\end{array}$ & $\begin{array}{l}11,670.99(\mathrm{EOD}) \text { and } \\
11,993.51 \text { (LOD) }\end{array}$ & $\operatorname{Gamma}(24$, scale $=500)$ & $\begin{array}{l}\text { Resource usage- [40], costs - } \\
{[41,42]}\end{array}$ \\
\hline
\end{tabular}




\begin{tabular}{|c|c|c|c|}
\hline Annual long-term care costs per case & $\begin{array}{l}\text { 6,000 (severe), 3,000 } \\
\text { (moderate), 1,000 (mild) }\end{array}$ & $\begin{array}{l}\text { Triangular(4000,6000,32000) (severe), } \\
\text { Triangular(2000,3000,4000) (moderate), } \\
\text { Triangular(500,1000,2000) (mild) }\end{array}$ & Based on [43-45] \\
\hline Maternal disease costs & $2,475.79$ & Triangular(367.08, 2475.79, 7341.59) & Based on [35] \\
\hline Vaccine administration cost per dose & 9.80 & Not tested & [46] \\
\hline Vaccine adverse reaction cost & $\begin{array}{l}42.42(\mathrm{GP}) \text { and } 468.55 \\
\text { (anaphylaxis) }\end{array}$ & $\operatorname{Gamma}(220$, scale $=2.13)$ (anaphylaxis) & Based on $[41,42]$ \\
\hline Award per litigation claim & $563,241.27$ & $\operatorname{Gamma}(5.63$, scale $=100043)$ & $\begin{array}{l}\text { Based on: base case -[47], } \\
\text { distribution- }[44,47-50]\end{array}$ \\
\hline \multicolumn{4}{|l|}{ Litigation } \\
\hline $\begin{array}{l}\text { Rate of successful litigation claims per } \\
\text { infant GBS case }\end{array}$ & 0.0137 & unif(0.011,0.0339) & Combination of $[2,47-51]$ \\
\hline $\begin{array}{l}\text { Proportion of successful litigation cases } \\
\text { being fatalities }\end{array}$ & 0.379 & unif(0.3411, 0.4169) & [48] \\
\hline
\end{tabular}


Maternal GBS infections were identified by linking laboratory confirmed cases of invasive disease (i.e. GBS isolated from a sterile site) reported to PHE through routine surveillance in England in 2014 to hospital admissions captured through NHS Digital Hospital Episode Statistics (HES). Pregnancy or recent childbirth (within 6 weeks of diagnosis) was identified in HES through assessment of maternity fields, clinical ICD-10 codes, admission method, medical specialty or surgical procedure codes [35]. Maternal GBS disease parameter values were based on HES data on maternal GBS sepsis (Appendix 1) and maternal life expectancy was based on the National Life Tables for the United Kingdom [55].

\section{Parameter values - Costs}

All costs were in $2015 £ \mathrm{GBP}$, with estimates from previous years inflated using Hospital and Community Health Services (HCHS) pay and prices index [56].

Healthcare costs for infant GBS cases in the first two years of life were based on resource utilisation data by Schroeder et al [40], in combination with NHS Reference data [42] and Unit Costs of Health and Social Care [41]. Details on parameter estimates are given in Appendix 1. Data on long-term sequelae costs are scarce; only one study reporting estimates for healthcare costs for very severe meningitis and sepsis sequelae was identified [43].

Litigation costs were sought from the NHS Litigation Authority through a Freedom of Information Request; the available data, however, were not disease-specific (Appendix 1). Estimates used in this study were the result of data synthesis from a number of different sources (Appendix 1). Furthermore, the model includes litigation costs only beyond the product of lost QALYs and ceiling ratio of cost per QALY gained, following current Department of Health practice (Peter Grove personal communication, 24 October 2016).

Healthcare costs for maternal GBS disease were derived from the corresponding hospital admission record during which the laboratory diagnosis was made. An average cost per 
maternal disease case was calculated weighing the relevant HRG codes recorded in HES according to their frequency (Appendix 1).

Potential adverse effects of vaccination were also considered. These included both mild effects requiring a GP visit and more serious adverse effects such as anaphylaxis (Appendix $1)$.

\section{Parameter values - Vaccine}

152 The base case scenario considered immunisation of pregnant women in the UK with a pentavalent vaccine (serotypes Ia, Ib, II, III and V). Women of at least 24 weeks of gestation would be offered the vaccine against GBS. Strain coverage by such a vaccine was estimated to be $96.2 \%$ based on the latest surveillance data [2] (Appendix 1). Vaccine uptake was set at $60 \%$ based on information from the pertussis maternal immunisation programme [57]. Data on vaccine efficacy are not currently available so our assumption of $85 \%$ was based on reported vaccine efficacy for other conjugate vaccines [37,38] (Appendix 1). Vaccine price is also currently unknown. Here, we tested different vaccine prices with the aim of identifying those for which a GBS vaccine would be cost-effective.

The size of the maternities cohort (excluding miscarriages) in combination with the vaccine uptake rate means an estimated 467,949 immunisations will occur annually in the UK. The costs of purchasing and administering the vaccine for this population was estimated in the model.

\section{Parameter values - Discounting}

Following JCVI guidelines [29] future costs and health outcomes were discounted at 3.5\% and a threshold of $£ 20,000$ per QALY gained was applied. A threshold of $£ 30,000$ per QALY 
gained was also explored as well as an alternative scenario of $£ 15,000$ per QALY at $1.5 \%$ discounting for both future costs and health outcomes.

\section{Sensitivity Analysis}

Through univariate sensitivity analysis, we explored the effect of individual parameters on the vaccine impact and vaccine cost-effectiveness, while we identified the threshold costeffective vaccine price for the base parameter values. Parameters were varied by $\pm 50 \%$, with some exceptions applying for cases where this variation was beyond their maximum/minimum possible values. We also explored the cumulative effect of groups of parameters - irrespective of disease onset or sequelae severity (overall values of: disease incidence, fatality rate, sequelae rate and cost per sequelae case and combination of: overall disease incidence and vaccine efficacy).

Scenario analysis was used to test assumptions excluded from the base case scenario.

Prevention of stillbirth and/or premature birth are important potential advantages of maternal immunisation over the current practice of risk factor-based IAP, however, such benefits are currently hypothetical. We tested the potential impact of a GBS vaccine on prevention of stillbirth and premature birth, both in combination and individually. In the investigation of stillbirth prevention, we accounted for averted cases having the life expectancy of healthy survivors. For preterm births, we accounted for the relevant healthcare costs. We also considered other scenarios offering additional health outcomes, including prevention of maternal deaths and effect of disease on the health of carers (predominantly parents; recent economic evaluation studies have accounted for the impact of disease on the quality of life of carers [41-43]). A scenario of decreased vaccine strain coverage, with a trivalent GBS 
vaccine used instead of the base case scenario assumption of a pentavalent vaccine was also explored. Parameters for all scenarios are available in Appendix 1 (Table 9).

Furthermore, Monte Carlo probabilistic sensitivity analysis of 5,000 iterations was carried out.The choice of parameter intervals and distributions (Table 1) was informed by data where possible. Beta distributions were selected for parameters bounded between zero and one and gamma distributions for parameters describing costs. Exceptions were made for parameters distributions were selected.

\section{Results}

\section{Deterministic Model Results}

204 In the base case scenario, we estimated that maternal GBS immunisation will prevent 369 cases of GBS in infants annually, including 179 cases with sequelae. Twenty one infant deaths will be averted and 103 maternal cases will also be avoided. In total, 563 life years will be gained from averted infant deaths and 232 from averted infant sequelae which would have resulted in premature mortality. The total gain in QALYs from infant disease will be 870. Exploration of the base case scenario showed the maximum vaccine price for which immunisation remains cost-effective to be $£ 54$ per vaccine dose at $£ 20,000$ / QALY gained.

211 The maximum vaccine price when a threshold of $£ 30,000$ per QALY was considered was $212 £ 71$. 
213 A variety of different vaccine prices were explored and the changing cost per QALY gained

214 is presented in Appendix 2 (Table 1). For our base case scenario, a vaccine price of $£ 54$ per

215 dose was adopted. The gross costs of vaccination were estimated at $£ 30.7$ million, which

216 includes the costs of buying and administering the vaccine. The net cost of vaccination to the

217 NHS and the PSS will be approximately $£ 17.4$ million, accounting for savings from the 218 reduced burden of disease.

219 The cost per QALY gained is $£ 19,953$, the cost per infant case prevented $£ 46,987$ and the 220 cost per death averted $£ 826,284$. The results of the base case scenario are summarised in Table 2.

\section{Sensitivity analysis results}

One-way sensitivity analysis identified a number of highly influential parameters (Error!

Reference source not found.), with overall disease incidence and vaccine price having the biggest effect on model results. Vaccine uptake did not alter the incremental costeffectiveness of the maternal immunisation strategy with risk factor-based IAP in comparison with risk factor-based IAP alone, with both costs and health effects being multiples of this rate and cost per QALY gained remaining unchanged.

\section{Scenario analysis}

230 Several scenarios were explored as alternatives to the assumptions of the base case (Appendix 2, Table 2). Potential prevention of stillbirths and/ or preterm births by the GBS vaccine, for instance, would increase its added benefits, making it more cost-effective. With a theoretical $1 \%$ of stillbirths assumed to be vaccine-preventable, the maximum cost-effective vaccine price was $£ 94$ ( $£ 54$ per dose in the base case). A similar percentage of vaccinepreventable (surviving) preterm births had a lesser impact, with the maximum cost-effective 
price rising to $£ 59$. A combination of both resulted in a maximum cost-effective price of

$237 £ 100$.

238 Table 2. Deterministic model results for base case scenario.

\begin{tabular}{|c|c|c|c|}
\hline Health outcomes & $\begin{array}{l}\text { Risk factor-based } \\
\text { IAP alone } \\
\text { (current strategy) }\end{array}$ & $\begin{array}{l}\text { Maternal } \\
\text { immunisation } \\
\text { with risk factor- } \\
\text { based IAP } \\
\text { (proposed } \\
\text { strategy) }\end{array}$ & $\begin{array}{l}\text { Incremental } \\
\text { benefits of } \\
\text { proposed } \\
\text { immunisation } \\
\text { strategy }\end{array}$ \\
\hline Infant disease cases & 753 & 384 & -369 \\
\hline Infant cases with sequelae & 365 & 186 & -179 \\
\hline Infant deaths & 43 & 22 & -21 \\
\hline Maternal disease cases & 210 & 107 & -103 \\
\hline $\begin{array}{l}\text { Life-years lost to infant deaths } \\
\text { (discount rate of } 3.5 \% \text { applied) }\end{array}$ & 1,148 & 585 & -563 \\
\hline $\begin{array}{l}\text { Life-years lost to infant sequelae } \\
\text { which would have resulted in } \\
\text { premature mortality (discount rate } \\
\text { of } 3.5 \% \text { applied) }\end{array}$ & 473 & 241 & -232 \\
\hline $\begin{array}{l}\text { QALY loss (discount rate of } \\
3.5 \% \text { applied) }\end{array}$ & 1,773 & 903 & -870 \\
\hline Costs (£ millions) & $\begin{array}{l}\text { Risk factor-based } \\
\text { IAP alone } \\
\text { (current strategy) }\end{array}$ & $\begin{array}{l}\text { Maternal } \\
\text { immunisation } \\
\text { with risk factor- } \\
\text { based IAP } \\
\text { (proposed } \\
\text { strategy) }\end{array}$ & $\begin{array}{l}\text { Incremental costs } \\
\text { of proposed } \\
\text { immunisation } \\
\text { strategy }\end{array}$ \\
\hline Maternal immunisation & - & 30.7 & 30.7 \\
\hline $\begin{array}{l}\text { Infant GBS disease (both short- } \\
\text { and long-term costs) }\end{array}$ & 25.2 & 12.8 & -12.4 \\
\hline Litigation & 1.5 & 0.8 & -0.7 \\
\hline Maternal GBS disease & 0.5 & 0.3 & -0.2 \\
\hline
\end{tabular}




\begin{tabular}{|l|c|c|c|}
\hline Total & 27.2 & 44.6 & 17.4 \\
\hline Cost-effectiveness measures & & & $\begin{array}{l}\text { Incremental cost- } \\
\text { effectiveness of } \\
\text { proposed } \\
\text { immunisation } \\
\text { strategy }\end{array}$ \\
\hline Cost per QALY gained & & & 19,953 \\
\hline Cost per case prevented & & & 46,987 \\
\hline Cost per death averted & & & 826,284 \\
\hline Cost per life-year gained & & & 21,828 \\
\hline
\end{tabular}

Cohort size: 776,352 livebirths, 3,563 stillbirths. Stillbirths were only included in the estimation of immunisation costs. Maternal immunisation parameters: vaccine price $=£ 54 /$ dose, vaccine efficacy $=$ $85 \%$, vaccine strain coverage $=96.2 \%$, vaccine uptake rate $=60 \%$. Litigation costs included in the table exclude those already accounted for through lost QALYs (Department of Health practice). IAP: intrapartum antibiotic prophylaxis, QALY: quality-adjusted life year, GBS: group B Streptococcus

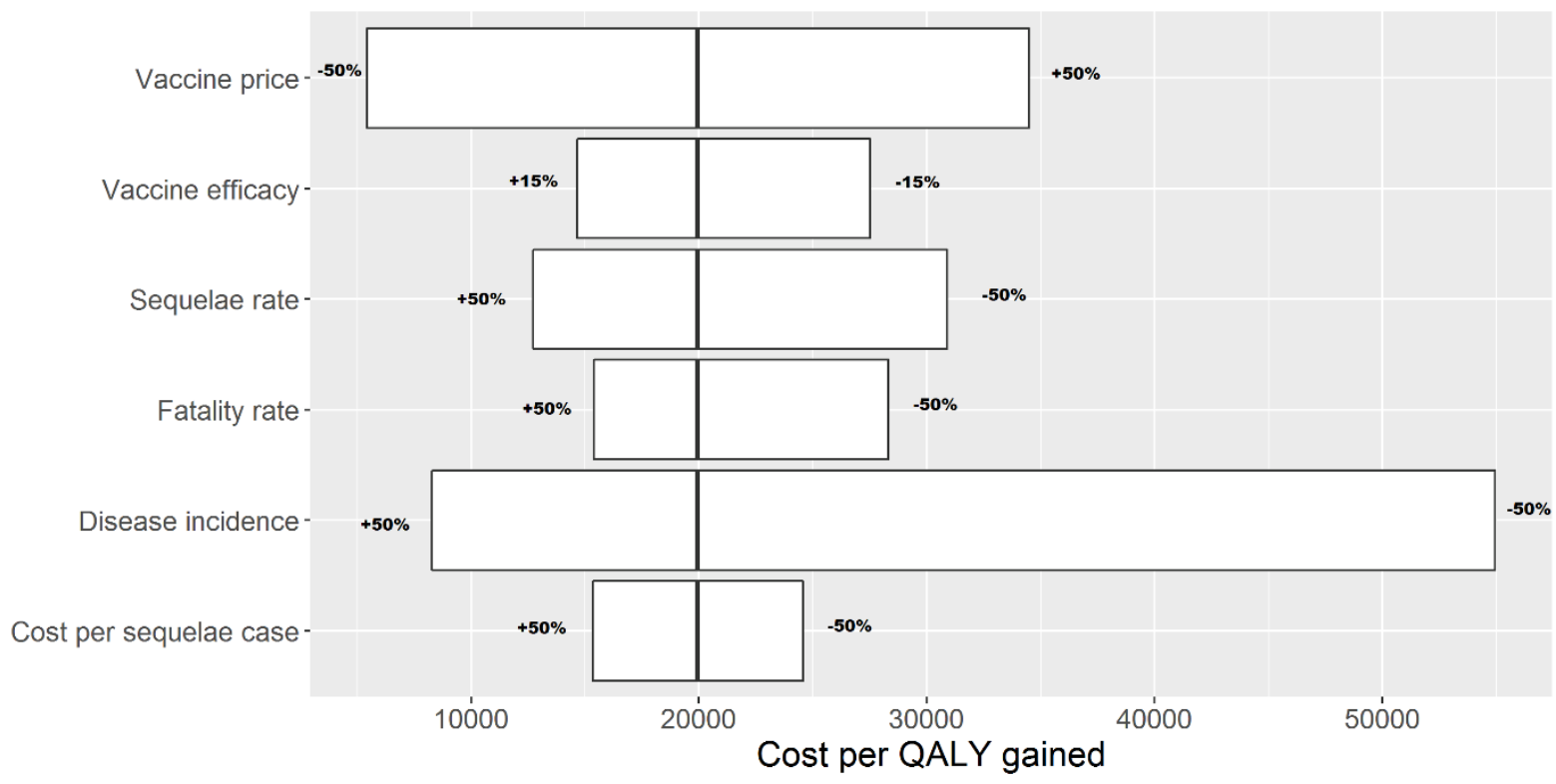

Figure 2. Results of one-way (vaccine price, vaccine efficacy) and multi-way (overall: sequelae rate, fatality rate, disease incidence and cost per sequelae case) sensitivity analysis. Base value estimates were varied by $\pm 50 \%$ with the exception of vaccine efficacy which was varied by \pm 0.15 (maximum value $=1$ ). Base case scenario cost per QALY $(£ 19,953)$ is displayed by the middle line in 
each bar. Parameters displayed here are those whose alteration had an impact in the cost per QALY of at least 20\%. The impact of EOD and LOD incidence is presented here in a cumulative way, though both parameters have an individual effect on the cost per QALY at beyond $20 \%$ its base case value (£19,953). QALY: quality-adjusted life year, EOD: early onset disease, LOD: late onset disease

To date, no maternal deaths caused by GBS have been reported in the UK $[35,58]$.

Considering the possibility that some maternal fatalities could occur [59], we accounted for a maternal fatality rate of $1 \%$ among maternal GBS cases. The GBS vaccine was only marginally more cost-effective in this scenario with the threshold cost-effective price (rounded to the nearest GBP) remaining the same.

We considered the potential effect of health spillovers for cases with sequelae and for fatalities in one of the scenarios we explored, adjusting this for those displaced by funding the intervention [60] (Appendix 1). Results showed the vaccine programme to be more costeffective, increasing the threshold vaccine price by $£ 6$ (Appendix 2, Table 2).

A 'most favourable' scenario incorporating all of the above increased the threshold vaccine price to $£ 107$.

The case of a trivalent GBS vaccine (Appendix 1) was explored and compared with the base case assumption of a pentavalent vaccine (Appendix 2, Table 2). The threshold vaccine price at $£ 20 \mathrm{k} /$ QALY was $£ 8$ less than the pentavalent vaccine.

Finally, an alternative $1.5 \%$ discount rate for both future costs and health outcomes with a $£ 15,000$ / QALY threshold scenario was explored to reflect discussions on the appropriate threshold $[61,62]$. Comparing the base case results with this scenario, the vaccine became 
273 in the base case).

\section{$274 \quad$ Probabilistic sensitivity analysis}

275 Consistency of results for the base case scenario (assuming $£ 54$ per dose) was explored in the

276 probabilistic sensitivity analysis, where parameter distributions were set to reflect estimates'

277 variations perceived as realistic. Uncertainty guidelines require at least $90 \%$ of iterations to

278 be under the $£ 30,000$ threshold [29]. Of the 5,000 iterations that were run, $92.24 \%$ fell under

279 the $£ 30,000$ threshold of cost per QALY gained (Error! Reference source not found.),

280 while a slightly higher vaccine price of $£ 55$ per dose showed $90.66 \%$ of iterations below the

$281 £ 30,000$ threshold. Model outcomes were highly dependent on vaccine price Figure 4. 


\section{Cost-effectiveness}

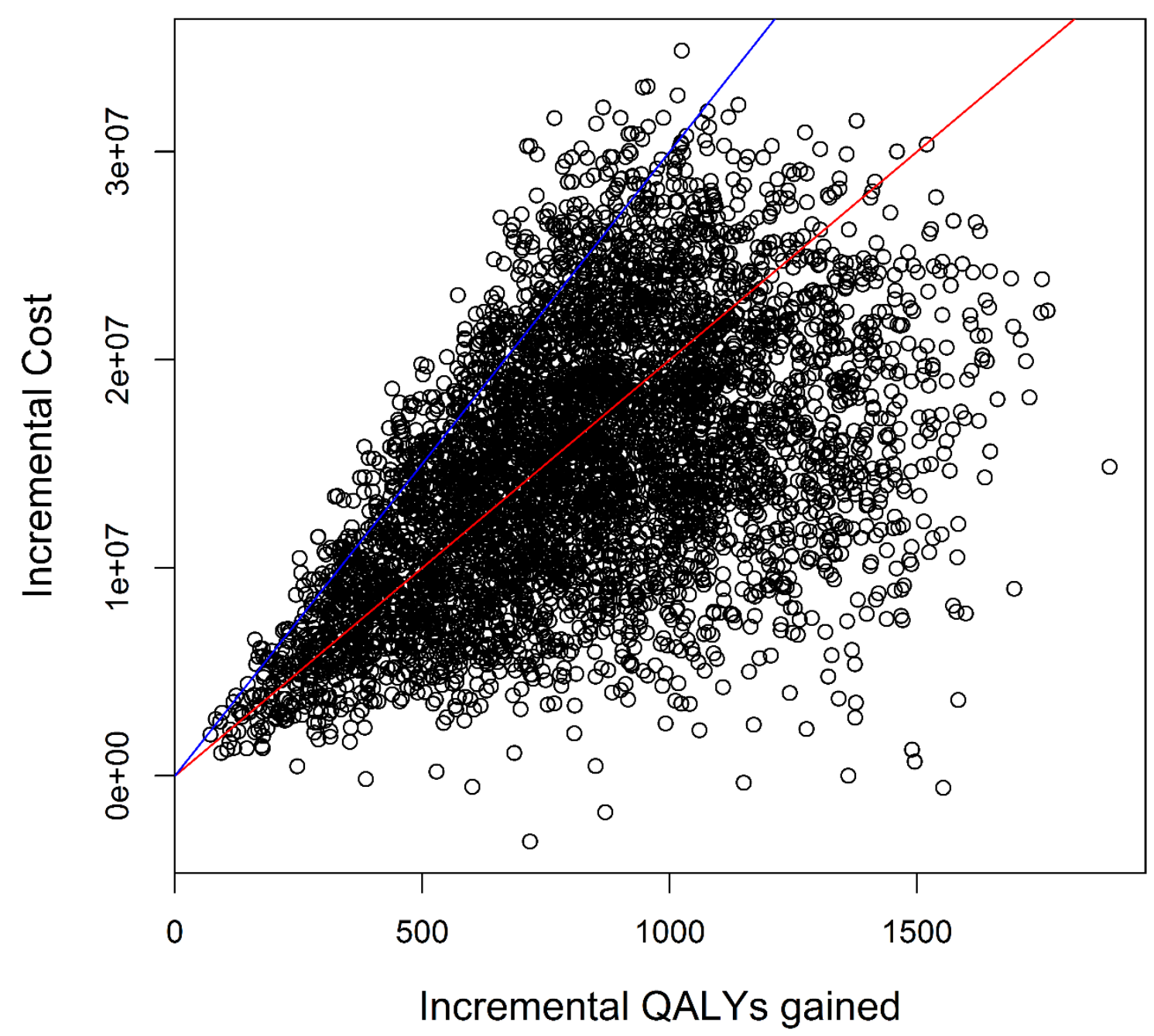

Figure 3. Monte Carlo probabilistic sensitivity analysis of 33 parameters, 5,000 iterations, for

287 base case scenario. The incremental cost ( $($ ) of the maternal immunisation strategy with risk factorbased IAP comparing with that of risk factor-based IAP alone is plotted in the $\mathrm{y}$ axis, with the $\mathrm{x}$ axis displaying the incremental QALYs gained. Of the 5,000 iterations $92.24 \%$ fall below the $£ 30,000$ ceiling ratio (blue line) of cost per QALY gained and 56.62\% below the $£ 20,000$ threshold (red line). 


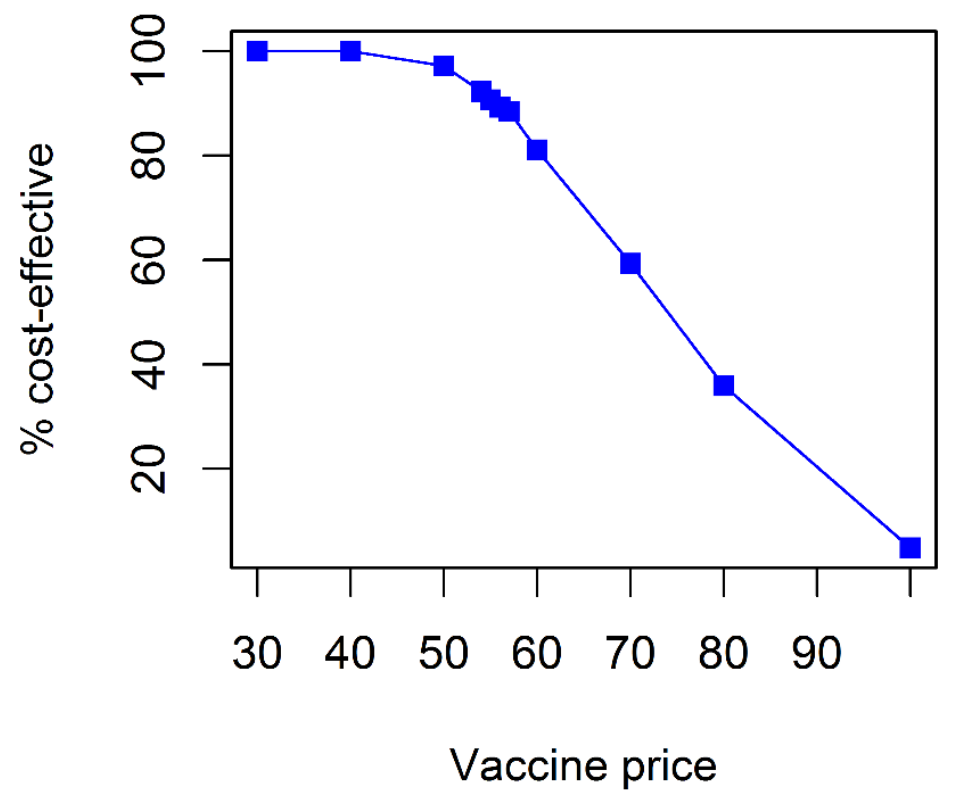

294 Figure 4. Effect of vaccine price (£) on the percentage of Monte Carlo iterations (total of 5,000) for which the immunisation strategy is cost-effective (threshold of $£ 30,000$ per QALY gained). Discount rate is $3.5 \%$ for both future costs and health outcomes. Vaccine price per dose for the base case scenario is $£ 54$. QALY: quality-adjusted life year

Investigating the effect of the interplay between vaccine efficacy and overall disease incidence on the probabilistic sensitivity analysis results, it is evident that uncertainty in the cost per QALY gained is mainly driven by vaccine efficacy (The cost-effectiveness acceptability curve is presented in Error! Reference source not found.. The latter exhibits the changing incremental cost-effectiveness of the maternal immunisation strategy with risk 304 factor-based IAP in comparison with risk factor-based IAP alone for the base case of parameter values (vaccine price of $£ 54$ per dose), for a changing ceiling ratio of cost per QALY gained. 


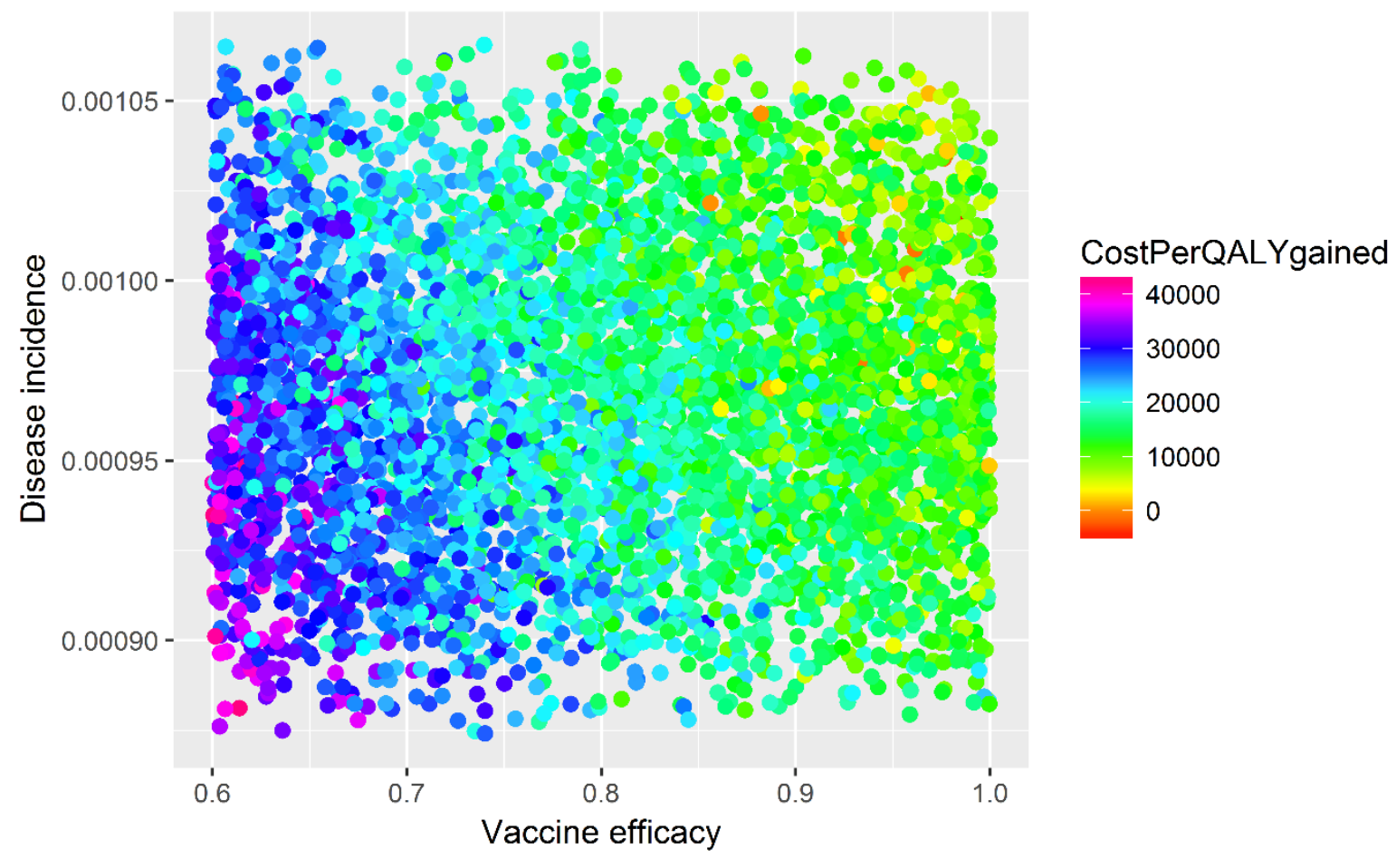

308 Figure 5. Comparison of overall disease incidence and vaccine efficacy as drivers of vaccine cost-

309 effectiveness, in Monte Carlo probabilistic sensitivity analysis of 5,000 iterations, where other

310 parameter values remain as in base case scenario. Vaccine price per dose for the base case scenario

311 is $£ 54$. Incremental cost (£) per QALY gained of the maternal immunisation strategy with risk factor-

312 based IAP comparing with that of risk factor-based IAP alone is represented by nodes of varying colour depending on value (colour guide on figure's right side). QALY: quality-adjusted life year 


\section{Cost-effectiveness acceptability curve}

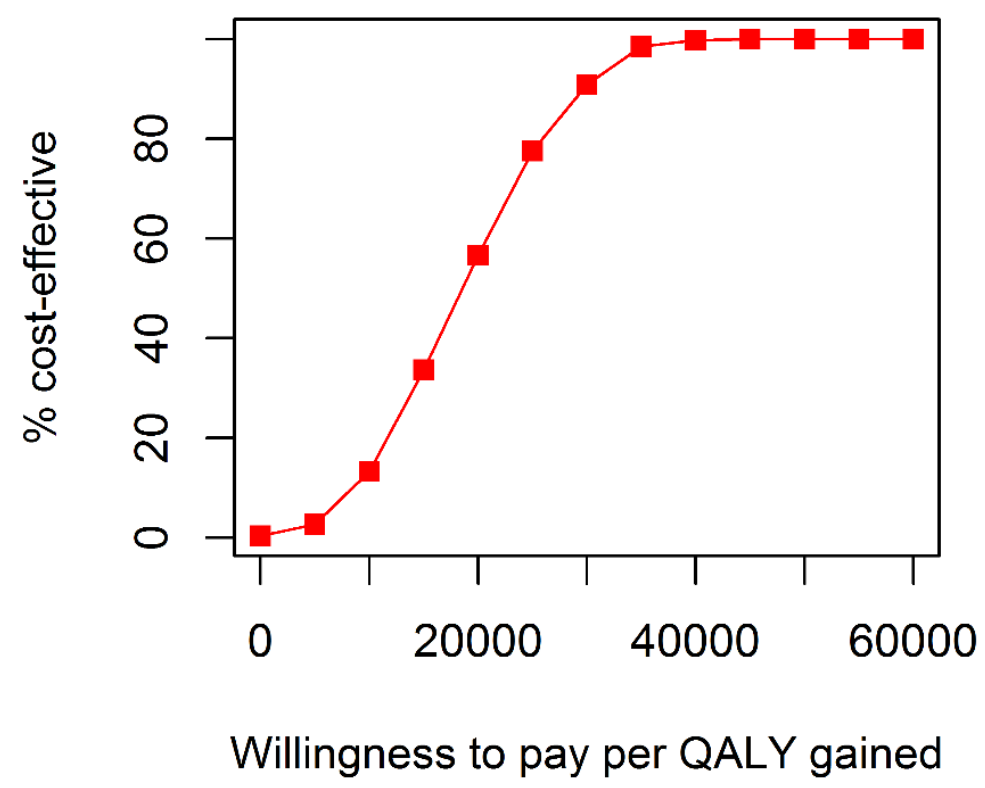

Figure 6. Cost-effectiveness acceptability curve of the base case scenario (future costs and health outcomes discount rate $=3.5 \%$ ). The graph displays the percentage of Monte Carlo iterations (total of 5,000 ) for which the immunisation strategy is cost-effective, depending on the willingness of the healthcare system to pay (in $£$ ) for each QALY gained. Vaccine price per dose in the base case scenario is $£ 54$. QALY: quality-adjusted life year

Discussion

Principal findings

A maternal immunisation strategy with risk factor-based IAP, is highly likely to be a cost-

324 effective intervention against infant GBS disease for the NHS, assuming the availability of a safe, effective vaccine that can be purchased and administered at a reasonable price. The proposed new strategy is compared to the current strategy of risk factor-based IAP alone. In 
the base case, we estimated that, with $60 \%$ coverage, 369 infant cases, 103 maternal cases and 21 infant deaths could be averted in a single birth cohort. Additional benefit would be achieved if coverage were closer to the $75 \%$ achieved recently in the maternal pertussis programme [63]. The threshold cost per dose was $£ 54$ at $£ 20,000 /$ QALY; at this price, the uncertainty rules are also met, with $92.24 \%$ of simulations in the probabilistic sensitivity analysis falling below $£ 30,000 / \mathrm{Q} A \mathrm{~L}$. Most of the alternative scenarios we investigated improved the cost-effectiveness of immunisation. Prevention of stillbirths and/ or preterm births would ). In contrast with Error! Reference source not found., where both parameters were varied by $50 \%$, here the disease incidence - for which there are recent and reliable data was only varied by $\pm 10 \%$. Vaccine efficacy, on the other hand, for which no data are available, was varied more, with values ranging from 0.6 to 1 to reflect this uncertainty. The cost-effectiveness acceptability curve is presented in Error! Reference source not found.. The latter exhibits the changing incremental cost-effectiveness of the maternal immunisation strategy with risk factor-based IAP in comparison with risk factor-based IAP

341 alone for the base case of parameter values (vaccine price of $£ 54$ per dose), for a changing ceiling ratio of cost per QALY gained. 


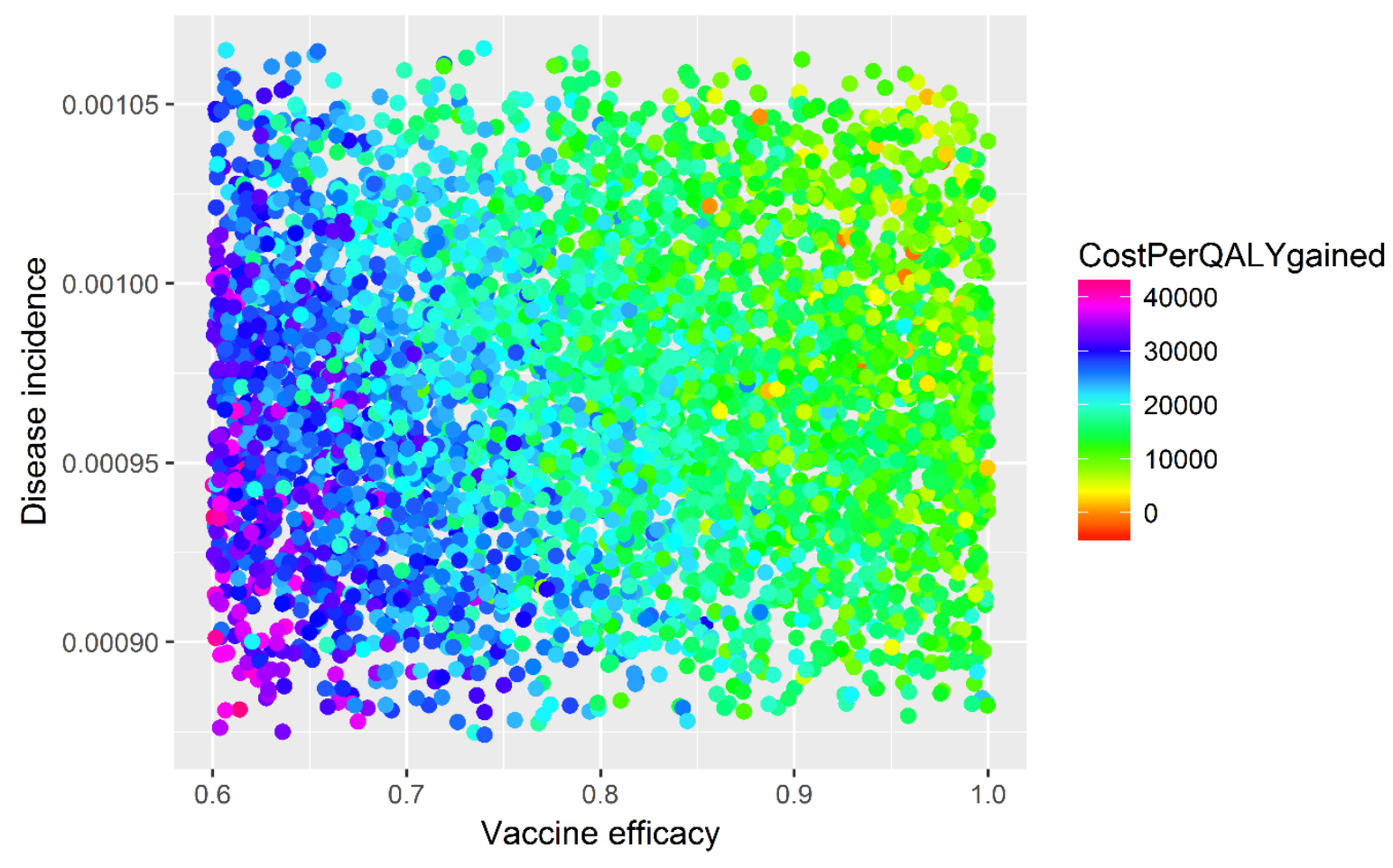

Figure 5. Comparison of overall disease incidence and vaccine efficacy as drivers of vaccine costeffectiveness, in Monte Carlo probabilistic sensitivity analysis of 5,000 iterations, where other parameter values remain as in base case scenario. Vaccine price per dose for the base case scenario is $£ 54$. Incremental cost $(£)$ per QALY gained of the maternal immunisation strategy with risk factorbased IAP comparing with that of risk factor-based IAP alone is represented by nodes of varying colour depending on value (colour guide on figure's right side). QALY: quality-adjusted life year 


\section{Cost-effectiveness acceptability curve}

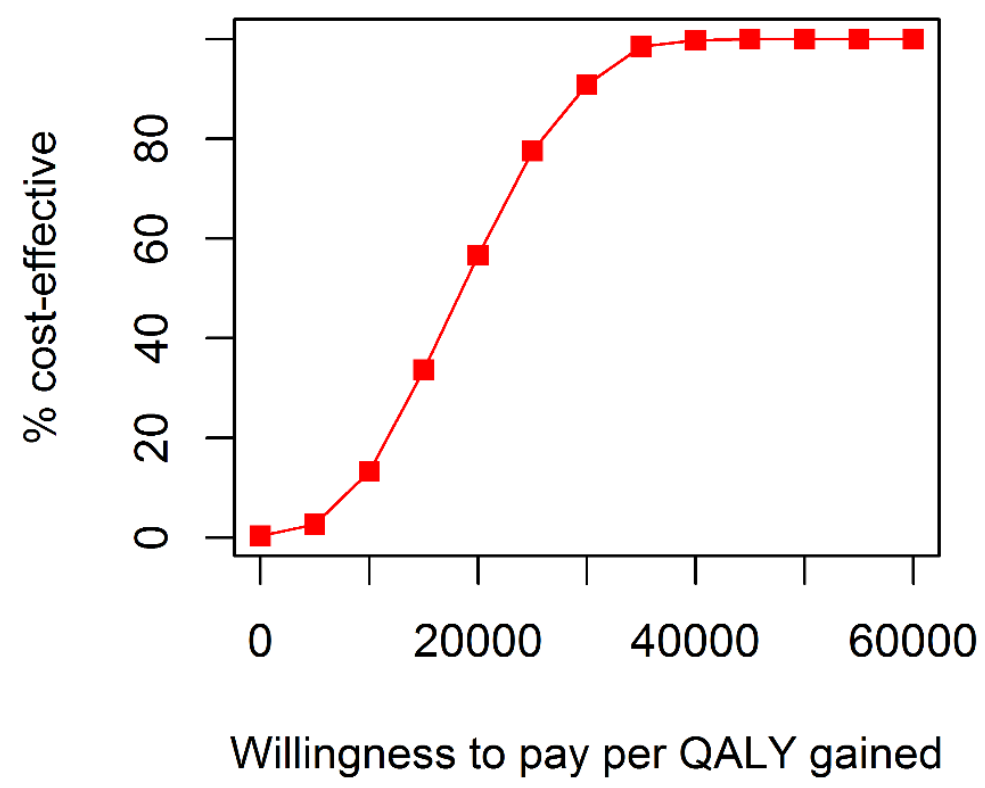

351 Figure 6. Cost-effectiveness acceptability curve of the base case scenario (future costs and health outcomes discount rate $\mathbf{3 . 5 \%}$ ). The graph displays the percentage of Monte Carlo iterations (total of 5,000 ) for which the immunisation strategy is cost-effective, depending on the willingness of the healthcare system to pay (in $£$ ) for each QALY gained. Vaccine price per dose in the base case scenario is $£ 54$. QALY: quality-adjusted life year

Discussion

Principal findings

A maternal immunisation strategy with risk factor-based IAP, is highly likely to be a costeffective intervention against infant GBS disease for the NHS, assuming the availability of a safe, effective vaccine that can be purchased and administered at a reasonable price. The proposed new strategy is compared to the current strategy of risk factor-based IAP alone. In 
the base case, we estimated that, with $60 \%$ coverage, 369 infant cases, 103 maternal cases and 21 infant deaths could be averted in a single birth cohort. Additional benefit would be achieved if coverage were closer to the $75 \%$ achieved recently in the maternal pertussis programme [63]. The threshold cost per dose was $£ 54$ at $£ 20,000 /$ QALY; at this price, the uncertainty rules are also met, with $92.24 \%$ of simulations in the probabilistic sensitivity analysis falling below $£ 30,000 / \mathrm{Q} A \mathrm{LY}$. Most of the alternative scenarios we investigated improved the cost-effectiveness of immunisation. Prevention of stillbirths and/ or preterm births would increase vaccine cost-effectiveness, while the prevention of maternal deaths from GBS sepsis would only have a minor impact, as this is considered to be rare. Both a trivalent and a pentavalent vaccine would be cost-effective, with the latter being clearly more attractive for both the health system and vaccine manufacturers. Accounting for the health benefits gained (and displaced) from reducing the strain on carers also makes the vaccine more cost-effective. The cumulative effect of including all vaccine-favourable scenarios more than doubles the threshold vaccine price.

\section{Strengths and limitations}

The inclusion of the latest UK surveillance data in this study [2] is a major strength.

Moreover, we included preliminary data on outcomes and sequelae among UK infant GBS survivors from an on-going study, an area previously lacking in evidence. We are conducting further research on the relation between quality of life and severity of sequelae in infants with GBS disease. Unlike other studies of the cost-effectiveness of GBS maternal vaccination, we accounted for maternal disease outcomes, litigation costs and health impact on carers. To the best of our knowledge, this is the first cost-effectiveness study on GBS considering displaced health spillover benefits. 
A key limitation is that we do not yet know the properties of the vaccine. Vaccine efficacy is currently unknown; given the experience with other conjugate vaccines, we would expect a GBS vaccine would demonstrate high efficacy over the course of the infant risk period for both EOD and LOD but this can only be estimated once a vaccine becomes available. We considered vaccination to be necessary in each pregnancy, with no enduring protection from vaccine given in a previous pregnancy. Studies of antibody persistence will be needed to determine whether this is necessary.

We did not consider any potential impact of maternal immunisation on maternal GBS colonisation. In one study non-pregnant women who received a GBS conjugate vaccine were found to have a significantly longer time to first vaginal acquisition than women in the control group [27], but no clear effect on colonisation was observed in a pregnancy trial with a different GBS conjugate vaccine [64]. We consider it unlikely that an immunisation programme targeting only pregnant women would have profound effects on the population biology of GBS even if a vaccine did influence carriage and so we chose a static decision tree model rather than a transmission dynamic model. However further research is necessary to fully understand the implications of a vaccine affecting colonisation, e.g. of vaccine selection pressure driving serotype replacement.

We did not have good data on the long-term economic cost of sequelae, estimates included in the model are speculative and results suggest they are influential. This issue could be addressed through appropriate follow-up studies of GBS survivors (our current follow-up study addresses prevalence but not cost of outcomes).

We investigated the added benefit of a maternal immunisation strategy where IAP is still used when pre-defined risk factors are identified. This does not address any potential savings which accrue if fewer antibiotics are administered and the important but less tangible benefits 
of reducing selection pressure which could lead to antibiotic resistance. We did not investigate other preventive strategies, such as universal screening for GBS colonisation, as we concentrated on the current UK context.

Finally, we also explored the effect of the healthcare system's willingness (and ability) to pay on cost-effectiveness, as a reminder of its influence on the analysis outcomes. We only considered the health provider's perspective, following standard NICE methodology and we did not investigate wider societal costs and benefits.

\section{Comparison with other studies}

A previous cost-effectiveness study on GBS disease in the UK [53] showed that a combination of vaccination with IAP for some maternal risk groups was amongst the most cost-effective of the tested strategies. Our analysis uses up-to-date parameter estimates, including increased incidence, and emphasises the added benefits of vaccination with riskbased IAP, rather than comparing a range of screening options. Other studies on the costeffectiveness of maternal immunisation have been conducted in South Africa [16]; subSaharan Africa [17] and the USA [18,19].

All of these studies concluded that GBS vaccination could be a cost-effective intervention, but found that disease incidence, vaccine efficacy and vaccine cost were key determinants, with most of the studies also including fatality rates in this list. The studies from the USA $[18,19]$ are more directly comparable to our study, as they investigate the added benefit of vaccination in terms of cost per QALY in a country with sophisticated healthcare. However, a key difference is that they compared vaccination in combination with screening-based IAP versus screening based IAP only (the current US standard of care). This prevents a head-tohead comparison, but it does appear that given the current incidence and standards of care, a UK programme might be more cost-effective than a maternal immunisation programme in the 
434

435

436

437

438

439

440

441

442

443

444

445

446

447

448

449

450

451

452

453

USA. In the future, a model comparison exercise to examine the differences in model assumptions, parameters and results could be of value.

\section{Conclusion}

A strategy of maternal immunisation in combination with risk-based intrapartum antibiotic prophylaxis against GBS disease in infants up to three months of age is likely to be costeffective in the UK, offering excellent prospects for reducing the burden of GBS disease.

\section{Acknowledgements}

We thank the following individuals for assistance: Hilary Rattue (St George's Hospital, University of London), Hannah Christensen (University of Bristol), Peter Grove (Department of Health), and Samantha Johnson (University of Leicester).

\section{Funding}

This study was funded by the Meningitis Research Foundation [project number 1302.0]. The funders had no role in the study design; collection, analysis, and interpretation of data; writing of the report; or decision to submit the article for publication.

\section{Conflicts of interest}


454 PTH has received grants from GlaxoSmithKline and Pfizer, outside the submitted work. TL

455 reports a grant from Pfizer to assess the burden of GBS infection, outside the submitted work.

456 MR leads PHE's Immunisation Hepatitis and Blood Safety Department, which provides

457 vaccine manufacturers with post-marketing surveillance reports on pneumococcal and

458 meningococcal infection which the companies are required to submit to the UK Licensing

459 authority in compliance with their Risk Management Strategy. A cost recovery charge is

460 made for these reports. HA reports funding from GlaxoSmithKline to attend a health

461 economics workshop.

\section{Contributors}

464 CT conceptualised the study. KG and CT designed the work. KG developed and

465 parameterised the models, carried out all analysis and prepared the first paper draft. KG and

466 CT prepared the final paper draft. CO, PH and TL provided data. All authors critically

467 revised the manuscript and approved the final version. KG is the guarantor of this study.

Appendix 1: Parameter estimation.

Appendix 2: Additional model results.

References Anthony, N. Ninis, P.T. Heath, E.P. Galiza, others, Incidence, Etiology, and Outcome of Bacterial Meningitis in Infants Aged< 90 Days in the United Kingdom and Republic of Ireland: 

e150-e157.

[2] C. O'Sullivan, T. Lamagni, A. Efstratiou, D. Patel, R. Cunney, M. Meehan, A. Reynolds, R. Campbell, L. Doherty, M. Boyle, E. Davies, P. Heath, P3 Group B Streptococcal (GBS) disease in UK and Irish infants younger than 90 days, 2014-2015, Arch. Dis. Child. 101 (2016) A2. doi:10.1136/archdischild-2016-310863.3.

[3] P.T. Heath, G. Balfour, A.M. Weisner, A. Efstratiou, T.L. Lamagni, H. Tighe, L.A. O'Connell, M. Cafferkey, N.Q. Verlander, A. Nicoll, Group B streptococcal disease in UK and Irish infants younger than 90 days, The Lancet. 363 (2004) 292-294.

[4] R. Libster, K.M. Edwards, F. Levent, M.S. Edwards, M.A. Rench, L.A. Castagnini, T. Cooper, R.C. Sparks, C.J. Baker, P.E. Shah, Long-term outcomes of group B streptococcal meningitis, Pediatrics. (2012) peds. 2011-3453.

[5] C. Nan, Z. Dangor, C. Cutland, M. Edwards, S. Madhi, M. Cunnington, Maternal group B Streptococcus-related stillbirth: a systematic review, BJOG Int. J. Obstet. Gynaecol. (2015) n/an/a. doi:10.1111/1471-0528.13527.

[6] J.E. Lawn, F. Bianchi-Jassir, N.J. Russell, M. Kohli-Lynch, C.J. Tann, J. Hall, L. Madrid, C.J. Baker, L. Bartlett, C. Cutland, M.G. Gravett, P.T. Heath, M. Ip, K. Le Doare, S.A. Madhi, C.E. Rubens, S.K. Saha, S. Schrag, A. Sobanjo-ter Meulen, J. Vekemans, A.C. Seale, Group B Streptococcal Disease Worldwide for Pregnant Women, Stillbirths, and Children: Why, What, and How to Undertake Estimates?, Clin. Infect. Dis. 65 (2017) S89-S99. doi:10.1093/cid/cix653.

[7] M. Cunnington, C. Kortsalioudaki, P. Heath, Genitourinary pathogens and preterm birth, Curr. Opin. Infect. Dis. 26 (2013) 219-230.

[8] C.D. Acosta, D.A. Harrison, K. Rowan, D.N. Lucas, J.J. Kurinczuk, M. Knight, Maternal morbidity and mortality from severe sepsis: a national cohort study, BMJ Open. 6 (2016) e012323.

[9] G. Kwatra, M.C. Cunnington, E. Merrall, P.V. Adrian, M. Ip, K.P. Klugman, W.H. Tam, S.A. Madhi, Prevalence of maternal colonisation with group $B$ streptococcus: a systematic review and meta-analysis, Lancet Infect. Dis. 16 (2016) 1076-1084.

[10] K. Le Doare, P.T. Heath, An overview of global GBS epidemiology, Vaccine. 31 (2013) D7-D12.

[11] T.L. Lamagni, C. Keshishian, A. Efstratiou, R. Guy, K.L. Henderson, K. Broughton, E. Sheridan, Emerging Trends in the Epidemiology of Invasive Group B Streptococcal Disease in England and Wales, 1991-2010, Clin. Infect. Dis. 57 (2013) 682-688. doi:10.1093/cid/cit337.

[12] Royal College of Obstetricians and Gynaecologists. The prevention of early-onset neonatal group B streptococcal disease., Green-Top Guidel. No 36. (2012). http://www.rcog.org.uk/files/rcog-corp/GTG36_GBS.pdf.

[13] The UK NSC recommendation on Group B Streptococcus screening in pregnancy, 2017. https://legacyscreening.phe.org.uk/groupbstreptococcus [Accessed 27 November 2017].

[14] M. Kobayashi, S.J. Schrag, M.R. Alderson, S.A. Madhi, C.J. Baker, A. Sobanjo-ter Meulen, D.C. Kaslow, P.G. Smith, V.S. Moorthy, J. Vekemans, WHO consultation on group B Streptococcus vaccine development: Report from a meeting held on 27-28 April 2016, Vaccine. (2016).

[15] T.E. Colbourn, C. Asseburg, L. Bojke, Z. Philips, N.J. Welton, K. Claxton, A.E. Ades, R.E. Gilbert, Preventive strategies for group $B$ streptococcal and other bacterial infections in early infancy: cost effectiveness and value of information analyses, BMJ. 335 (2007) 655. doi:10.1136/bmj.39325.681806.AD.

[16] S.-Y. Kim, L.B. Russell, J. Park, J.R. Verani, S.A. Madhi, C.L. Cutland, S.J. Schrag, A. Sinha, Costeffectiveness of a potential group $B$ streptococcal vaccine program for pregnant women in South Africa, Vaccine. 32 (2014) 1954-1963.

[17] L.B. Russell, S.-Y. Kim, B. Cosgriff, S.R. Pentakota, S.J. Schrag, A. Sobanjo-ter Meulen, J.R. Verani, A. Sinha, Cost-effectiveness of maternal GBS immunization in low-income sub-Saharan Africa, Vaccine. (2017). doi:10.1016/j.vaccine.2017.07.108. 
[18] G. Oster, J. Edelsberg, K. Hennegan, C. Lewin, V. Narasimhan, K. Slobod, M.S. Edwards, C.J. Baker, Prevention of group B streptococcal disease in the first 3 months of life: Would routine maternal immunization during pregnancy be cost-effective?, Vaccine. 32 (2014) 4778-4785.

[19] S.-Y. Kim, C. Nguyen, L.B. Russell, S. Tomczyk, F. Abdul-Hakeem, S.J. Schrag, J.R. Verani, A. Sinha, Cost-effectiveness of a potential group $B$ streptococcal vaccine for pregnant women in the United States, Vaccine. 35 (2017) 6238-6247. doi:10.1016/j.vaccine.2017.08.085.

[20] Office for National Statistics. Statistical bulletin: Births in England and Wales, 2014, 2015.

[21] Northern Ireland Statistics \& Research Agency. Vital Statistics. Births. Table 3.10. Live births, stillbirths and maternities, by sex of child, marital status of parents and age of mother,2012, n.d.

[22] National Records of Scotland. Vital events Reference Tables 2014. Section 3: Births. Table 3.14; 2014., n.d. http://www.nrscotland.gov.uk/_les//statistics/vital-events-reftables/2014/section3/14-vital-events-ref-tab-3-14.pdf [Accessed 27 May 2016].

[23] Office for National Statistics. Statistical bulletin: National Life Tables, United Kingdom 20122014., 2015.

[24] Northern Ireland Statistics \& Research Agency. Registrar General Annual Report 2014. Stillbirths and Infant Deaths., n.d. Available from : http://www.nisra.gov.uk/demography/default.asp99.htm [Accessed 27 May 2016].

[25] General Register Office for Scotland. Vital events reference tables 2012. Section 4: Stillbirths and infant deaths. Table 4.1, 2013.

[26] Royal College of Obstetricians and Gynaecologists, Royal College of Obstetricians and Gynaecologists.Group B Streptococcal Disease, Early-onset, (2017).

[27] National Institute of Allergy and Infectious Diseases (NIAID). A Phase II Randomized, DoubleBlinded, Comparative Clinical Trial for a Group B Streptococcus Serotype III-Tetanus Toxoid (GBS III-TT) Vaccine to Prevent Vaginal Acquisition of GBS Type III, (2009). https://clinicaltrials.gov/ct2/show/study/NCT00128219?term=GBS+studies\&sect=X470156 [Accessed 7 August 2016].

[28] S.A. Madhi, C.L. Cutland, L. Jose, A. Koen, N. Govender, F. Wittke, M. Olugbosi, A. Sobanjo-ter Meulen, S. Baker, P.M. Dull, Safety and immunogenicity of an investigational maternal trivalent group $B$ streptococcus vaccine in healthy women and their infants: a randomised phase $1 \mathrm{~b} / 2$ trial, Lancet Infect. Dis. 16 (2016) 923-934.

[29] JCVI. Code of practice June 2013, n.d. https://www.gov.uk/government/uploads/system/uploads/attachment_data/file/224864/JCVI _Code_of_Practice_revision_2013_-_final.pdf [Accessed 27 November 2014].

[30] Office for National Statistics. Statistical bulletin: Births in England and Wales, 2014, 2015.

[31] Northern Ireland Statistics \& Research Agency. Vital Statistics. Births. Table 3.10. Live births, stillbirths and maternities, by sex of child, marital status of parents and age of mother,2012, n.d.

[32] Northern Ireland Statistics \& Research Agency. Registrar General Annual Report 2014. Stillbirths and Infant Deaths., n.d. http://www.nisra.gov.uk/demography/default.asp99.htm [Accessed 27 May 2016].

[33] General Register Office for Scotland. Vital events reference tables 2012. Section 4: Stillbirths and infant deaths. Table $4.1 ; 2013$. Available from: http://www.groscotland.gov.uk/files2/stats/ve-ref-tables-2012/ve12-t4-1.pdf [Accessed 30 June 2014]., n.d.

[34] R.T. Katz, Life expectancy for children with cerebral palsy and mental retardation: implications for life care planning, NeuroRehabilitation. 18 (2003) 261-270.

[35] T. Lamagni, R. Guy, C. Wloch, N. Shetty, V. Chalker, A. Johnson, Estimating the burden of group B streptococcal (GBS) maternal sepsis in England. Federation of Infection Societies (FIS) Annual Conference and the 10th Healthcare Infection Society (HIS) International Conference 2016; 6 November 2016; Edinburgh, (n.d.).

[36] Public Health England, Vaccine Update, Issue 217, 2014. 
[37] G. Amirthalingam, N. Andrews, H. Campbell, S. Ribeiro, E. Kara, K. Donegan, N.K. Fry, E. Miller, M. Ramsay, Effectiveness of maternal pertussis vaccination in England: an observational study, The Lancet. 384 (2014) 1521-1528.

[38] C.L. Trotter, J. McVernon, M.E. Ramsay, C.G. Whitney, E.K. Mulholland, D. Goldblatt, J. Hombach, M.-P. Kieny, Optimising the use of conjugate vaccines to prevent disease caused by Haemophilus influenzae type b, Neisseria meningitidis and Streptococcus pneumoniae, Vaccine. 26 (2008) 4434-4445.

[39] J. Mohle-Boetani, A. Schuchat, B. Plikaytis, J. Smith, C. Broome, Comparison of prevention strategies for neonatal group b streptococcal infection: A population-based economic analysis, JAMA. 270 (1993) 1442-1448. doi:10.1001/jama.1993.03510120064032.

[40] E.-A. Schroeder, S. Petrou, G. Balfour, O. Edamma, P.T. Heath, The economic costs of Group B Streptococcus (GBS) disease: prospective cohort study of infants with GBS disease in England, Eur. J. Health Econ. 10 (2009) 275-285.

[41] L. Curtis, Unit Costs of Health and Social Care 2014, n.d.

[42] Department of Health. NHS reference costs 2013-2014, n.d. https://www.gov.uk/government/publications/nhs-reference-costs-2013-to-2014 [Accessed 27 April 2016].

[43] C. Wright, R. Wordsworth, L. Glennie, Counting the cost of meningococcal disease. Scenarios of Severe Meningitis and Septicemia, Pediatr. Drugs. 15 (2013) 49-58.

[44] H. Christensen, C.L. Trotter, M. Hickman, W.J. Edmunds, others, Re-evaluating cost effectiveness of universal meningitis vaccination (Bexsero) in England: modelling study, BMJ. 349 (2014) g5725.

[45] S. Petrou, S. Johnson, D. Wolke, N. Marlow, The association between neurodevelopmental disability and economic outcomes during mid-childhood., Child: care, health and development. 39 (2013) 345-357.

[46] NHS Employers. Vaccination and immunisation programmes 2016/17. Guidance and audit requirements, May 2016, n.d. http://www.nhsemployers.org/ /media/Employers/Documents/Primary [Accessed 1 June 2016].

[47] NHS Litigation Authority. Freedom of Information Request F/2649., (n.d.).

[48] J.E. Raine, An analysis of successful litigation claims in children in England, Arch. Dis. Child. 96 (2011) 838-840.

[49] G. Sen, J. Keene, J. Raine, An analysis of successful litigation claims in childhood fatalities in England, Eur. J. Pediatr. 171 (2012) 1657-1660.

[50] Meningitis Research Foundation. Response to the JCVI interim position statement on the use of Bexsero meningococcal B vaccine in the UK, (n.d.).

[51] D. Holt, S. Halket, J. De Louvois, D. Harvey, Neonatal meningitis in England and Wales: 10 years on, Arch. Dis. Child.-Fetal Neonatal Ed. 84 (2001) F85-F89.

[52] R.T. Katz, Life expectancy for children with cerebral palsy and mental retardation: implications for life care planning, NeuroRehabilitation. 18 (2003) 261-270.

[53] T. Colbourn, C. Asseburg, L. Bojke, Z. Philips, K. Claxton, A. Ades, R. Gilbert, Prenatal screening and treatment strategies to prevent group $B$ streptococcal and other bacterial infections in early infancy: cost-effectiveness and expected value of information analyses., Health Technol. Assess. 11 (2007).

[54] R.K. Eyman, H.J. Grossman, R.H. Chaney, T.L. Call, The life expectancy of profoundly handicapped people with mental retardation, N. Engl. J. Med. 323 (1990) 584-589.

[55] Office for National Statistics. National Life Tables: United Kingdom. 2015., (n.d.).

[56] L. Curtis, A. Burns, Unit Costs of Health and Social Care 2015. Personal Social Services Research Unit, The University of Kent, (n.d.).

[57] Public Health England, Vaccine Update, Issue 217, 2014. 
[58] A. Kalin, C. Acosta, J.J. Kurinczuk, P. Brocklehurst, M. Knight, Severe sepsis in women with group B Streptococcus in pregnancy: an exploratory UK national case-control study, BMJ Open. 5 (2015) e007976.

[59] J. Hall, N.H. Adams, L. Bartlett, A.C. Seale, T. Lamagni, F. Bianchi-Jassir, J.E. Lawn, C.J. Baker, C. Cutland, P.T. Heath, M. Ip, K. Le Doare, S.A. Madhi, C.E. Rubens, S.K. Saha, S. Schrag, A. Sobanjo-ter Meulen, J. Vekemans, M.G. Gravett, Maternal Disease With Group B Streptococcus and Serotype Distribution Worldwide: Systematic Review and Meta-analyses, Clin. Infect. Dis. 65 (2017) S112-S124. doi:10.1093/cid/cix660.

[60] H. Al-Janabi, J. Van Exel, W. Brouwer, J. Coast, A Framework for Including Family Health Spillovers in Economic Evaluation, Med. Decis. Making. 36 (2016) 176-186. doi:10.1177/0272989X15605094.

[61] The Department of Health Guidance Manual to Impact Assessments, (2015).

[62] K. Claxton, S. Martin, M. Soares, N. Rice, E. Spackman, S. Hinde, N. Devlin, P.C. Smith, M. Sculpher, Methods for the estimation of the National Institute for Health and Care Excellence cost-effectiveness threshold., Health Technol. Assess. Winch. Engl. 19 (2015) 1.

[63] Public Health England. Pertussis Vaccination Programme for Pregnant Women: vaccine coverage estimates in England, April to August 2014, n.d. https://www.gov.uk/government/publications/pertussis-immunisation-in-pregnancy-vaccinecoverage-estimates-in-england-october-2013-to-march-2014/pertussis-vaccinationprogramme-for-pregnant-women-vaccine-coverage-estimates-in-england-april-to-august2014\#results [Accessed 29 September 2017].

[64] S.A. Madhi, C.L. Cutland, L. Jose, A. Koen, N. Govender, F. Wittke, M. Olugbosi, A. Sobanjo-ter Meulen, S. Baker, P.M. Dull, Safety and immunogenicity of an investigational maternal trivalent group $B$ streptococcus vaccine in healthy women and their infants: a randomised phase $1 \mathrm{~b} / 2$ trial, Lancet Infect. Dis. 16 (2016) 923-934. 